\title{
AN EXPERIMENTAL AND COMPUTATIONAL STUDY ON THERMAL CONDUCTIVITY OF MARBLE PARTICLE FILLED EPOXY COMPOSITES
}

\author{
Subhrajit Ray ${ }^{1, *}$, Arun Ku. Rout ${ }^{2}$ and Ashok Ku. Sahoo ${ }^{3}$ \\ ${ }^{1}$ School of Mechanical Engineering, KIIT University, Bhubaneswar 751024, India \\ ${ }^{2}$ Department of Production Engineering, VSSUT, Burla-768018, India \\ ${ }^{3}$ School of Mechanical Engineering, KIIT University, Bhubaneswar 751024, India \\ *E-mail : subhrajitmech@gmail.com
}

\begin{abstract}
The present research establishes the experimental, theoretical and computational investigation on the thermal conductivity improvement of marble powder filled epoxy composites. The proposed model found to be the alternative to use the industrial by-product for successful manufacturing of new class of composites in view of heat conductivity capacity. Unitherm. ${ }^{\text {TM }}$ Model 2022 is used as per ASTM-E-1530 standard to measure the thermal conductivity of marble filled epoxy composite by the guarded heat flow test method. Finite element software package ANSYS is used to estimate the conductivity by the computational method. Three-dimensional sphere-incube lattice models are implemented to simulate the microstructure of marble powder filled composites with different concentrations. With the addition of $1.4 \mathrm{Vol} . \%$ of marble particle, the thermal conductivity of epoxy is increased by about $4.9 \%$ and with the addition of 6.5 vol\% of filler, an improvement of about $20.1 \%$ in thermal conductivity of epoxy is observed. This study reveals an improvement of thermal conductivities of epoxy based marble powder filled composites. The experimental conductivity values are compared with the existing models and computational model. The values recorded using finite element method (FEM) shows a good agreement.
\end{abstract}

Keywords: Thermal conductivity, Epoxy, marble powder, FEM

(C) RASĀYAN. All rights reserved

\section{INTRODUCTION}

In recent years commonly used polymers such as polyvinyl chloride, polyethylene, and polypropylene are found to be a good insulator of heat and electricity. For real-world engineering problems in electronic industry, composites with high thermal conductivity are required. To overcome the difficulty some conventional metallic filler is added with resin. This improves the conductivity of composites for the microelectronic application. Marble is an ornamental stone created from limestone kept under pressure and heat in the earth's covering due to ecological processes. Chemically, marble is a crystalline stone containing mostly dolomite and calcite. Marble dust plays the role of useful substance as a filler material in several applications like landfilling, making of bricks, cement manufacturing, sculpture industries, construction and another allied field of civil engineering applications. Previous researchers enlightened the use of marble dust as a useful constructional material. However, in the present work, it is examined to manufacture marble filled polymer matrix hybrid composite. Epoxy is an important polymer matrix for making such class of composite. Due to versatility in application polymer-based composites, epoxy plays an important role in last few decades as a research area.The composite samples considering various matrixes as polyester and epoxy with a different weight percentage of marble fillers were prepared. From the experimental study, it was observed that $60 \mathrm{wt} \%$ of marble filled epoxy composites showed better properties compared with conventional material. ${ }^{1}$ Marble particle was used as partial replacement of natural sand for manufacturing of bricks. The inclusion of marble particle improved the physical, chemical and mechanical properties of new class of bricks compared with conventional type. Environmental pollution was minimized due to use of marble dust and can be contributed to the economic impact. $^{2-5}$

Rasayan J. Chem., 11(1), 80-87(2018)

http://dx.doi.org/10.7324/RJC.2018.1111952 
The cast cooling temperature and how it affects the properties of particulate filled polymer composite were studied and the link between mode of cooling and application of composites were found. The best curing temperature was observed within $60-80^{\circ} \mathrm{C}$. As the curing temperature increased, the composite became brittle in nature. ${ }^{6,7}$ Ultrasonic properties of marble filled epoxy composites were investigated. ${ }^{8}$ The result showed a marginal improvement of ultrasonic and morphological property of marble-epoxy composites. However, the elastic properties of marble filled composites were found by ultrasonic method. The additions of marble waste for improvement of mechanical properties of concrete were studied. ${ }^{9}$ The experimental result showed the marble powder-sand mixture concrete resulted in improvement of compressive strength of concrete by decreasing the porosity of the concrete. Marble dust was utilized for the industrial application. The quality of industrial brick was found to be improved by the addition of marble powder into it. The marble dust was used as a partial replacement of clay, providing less waste generation. ${ }^{10}$ The positive temperature coefficient (PTC) behavior of polymers such as polyester, nylon etc. was investigated. ${ }^{11}$ The developed samples have used in electrodes and heaters in the industrial field. These materials have more thermal stability at elevated temperature. ${ }^{12}$ Presently, the particle size has been reduced and its effect on mechanical properties has been studied. The previous researchers have observed a decline in thermal conductivity of the polymer. ${ }^{13-16}$ The thermal conductivity improved in the parallel direction of orientation and reduced in the transverse direction. A marginal enhancement was recorded in the heat transfer capacity of poly-ethylene from about $0.35 \mathrm{~W} / \mathrm{m}-\mathrm{K}$ to $50 \mathrm{~W} / \mathrm{m}-\mathrm{K}$ for an isotropic material with a directional ratio of $50 .{ }^{17}$ The thermal conductivity of the composites was marginally affected by the interconnectivity of the filler materials. A development in thermal conductivity from $0.27 \mathrm{~W} / \mathrm{m}-\mathrm{K}$ to $2.5 \mathrm{~W} / \mathrm{m}-\mathrm{K}$ with the addition of $30 \mathrm{vol} \%$ talc added PP matrix composites was observed, whereas copper added composite showed a conductivity of $1.25 \mathrm{~W} / \mathrm{m}-\mathrm{K} .{ }^{18}$ The thermal conductivity test of epoxy modified with alumina and AIN particle were conducted based on Bruggeman's and Kanari's model. The AIN based composite showed higher thermal conductivity than that of alumina-based composites. ${ }^{19}$ This was mainly affected due to particle size and presence of oxygen in the sample. Changes in thermal conductivity of composites were noticed due to the shape of added particulates. ${ }^{20}$ The thermal conductivity of high-density polyethylene(HDPE) filled with tin particle up to $16 \%$ by volume was studied and an improvement in the conductivity from $23 \%$ to $101 \%$ was observed as compared with pure HDPE. ${ }^{21}$ Electrical conductivity was improved by the addition of $\mathrm{Al}_{2} \mathrm{O}_{3}$ nanoparticle with PVP solid polymer electrolyte film $(85: 15)$ at room temperature. ${ }^{22}$ Various percentage of $\mathrm{NaF}$ were incorporated into PAN. The experimental study concluded that, the composite containing 30\% NaF showed maximum thermal conductivity at room temperature. ${ }^{23}$ Researchers correlated the wear resistance and conductivity of same filler added composites. ${ }^{24}$ Copper and nickel particle filled epoxy and poly vinyl chloride (PVC) composite was prepared with different particle shape and size. ${ }^{25}$ The particles randomly distributed in the matrix. The result showed, the filler shape and type of arrangement marginally affect the thermal conductivity. The thermal properties of metal powder filled (0-24 vol \%) polyethylene composites were studied. ${ }^{26}$ The particle distribution remained homogeneous in $0-16$ vol $\%$, whereas at metallic fillers more than $16 \%$ tends to form conductive chains. The theoretical and empirical model was proposed to investigate the heat conductivity of two-phase composites. ${ }^{27}$ For these kinds of samples, the heat flow depends on the series or parallel arrangement providing upper and lower bound condition.

For parallel arranged conduction model:

$k_{c}=(1-\Phi) k_{e}+\Phi k_{m}$

Where $\mathrm{k}_{\mathrm{c}}, \mathrm{k}_{\mathrm{e}}$, and $\mathrm{k}_{\mathrm{m}}$ are the thermal conductivities of the composite epoxy and marble particle as matrix and filler respectively and $\Phi$ is the volume fraction of filler.

For series arranged conduction model:

$\frac{1}{k_{c}}=\frac{1-\Phi}{k_{e}}+\frac{\Phi}{k_{m}}$ 
Based on the rules of the mixture (ROM) the equations (1) and (2) are derived by Progelhof ${ }^{28}$.The correlations presented by equations (1) and (2) are derived on the basis of the rules of the mixture (ROM). A different structure based on series and parallel arranged conduction mechanism for particle filled polymers was predicted. ${ }^{29}$ According to this model, the expression becomes:

$$
\log k_{c}=\Phi c_{2} \log k_{m}+(1-\Phi) \log \left(c_{1} k_{\varepsilon}\right)
$$

Where $\mathrm{C}_{1}$ and $\mathrm{C}_{2}$ are constants determined from the experimental condition. $\mathrm{C}_{1}$ measures the secondary structure of the polymer and the effect of particulates on it. $\mathrm{C}_{2}$ measures the effect of the particle to make conductive chains. As the property of the particles concentrates to form conductive chains, the thermal conductivity of the composite changes and $\mathrm{C}_{2}$ tends towards one. The equation was later modified, considering the shape of the particle into account and semi-empirical model showed good result. ${ }^{30}$ However, sufficient experimental data required to find the constants for all composites. For randomly distributed particle composite, the equation for effective thermal conductivity is modified to:

$$
\frac{k}{k_{e}}=1+\frac{3 \Phi}{\left(\frac{k_{m}+2 k_{e}}{k_{m}-k_{e}}\right)-\Phi}
$$

Where $\mathrm{k}, \mathrm{k}_{\mathrm{e}}$, and $\mathrm{k}_{\mathrm{m}}$ are the effective thermal conductivities for composite, continuous phase epoxy matrix and dispersed-phase marble filler, respectively. Equation (4) is known as Maxwell equation for randomly oriented particle composite. ${ }^{31}$ The review of the literature reveals that there is the various utilization of marble powder in industrial application. However, its reinforcing potential and thermal conductivity property in composite have not been explored so far. There is no report available on thermosetting polymer as epoxy reinforced with marble particulate.

Study on the thermal conductivity of marble powder-epoxy composite is rare and relationship between the various properties (weight percentage, the arrangement of particles, properties at micro level etc.) and the thermal conductivity of the composite material is not explored so far. Apart from this, although some study reveals the improved thermal conductivity of polymer was achieved by adding metallic particle into it, yet it is to be seen how the incorporation of marble dust being an industrial low-cost waste impress the thermal behavior of epoxy composites. In view of above survey, the current research investigates the thermal conductivity of marble filled epoxy composites. The objective of present work includes fabrication of low-cost composite using marble dust as filler to improve the thermal conductivity of the composite. Epoxy having low thermal conductivity material (about $0.363 \mathrm{~W} / \mathrm{mK}$ ) is chosen due to its insulating property.

\section{Matrix material}

\section{EXPERIMENTAL}

The unmodified epoxy (LY 556) and hardener (HY 951) is supplied by Ciba Geigy Ltd., India. The chemical name of epoxy is Bisphenol A Diglycidyl Ether. Epoxy possesses a modulus of 3.42Gpa, and possesses a density of $1.10 \mathrm{gm} / \mathrm{cc}$ and thermal conductivity of $0.363 \mathrm{~W} / \mathrm{m}-\mathrm{K}$. Epoxy with hardener is mixed in a weight ratio of 10:1 as studied.

\section{Filler material (marble waste)}

Marble powder is considered as filler materials. The density of marble powder is $2.68 \mathrm{gm} / \mathrm{cc}$ and thermal conductivity $2.070 \mathrm{~W} / \mathrm{m}-\mathrm{K}$. The marble dust was brought from the School of Sculpture, KIIT University, India. The marble powders are kept in an electric oven at about $100^{\circ} \mathrm{C}$ for removing the moisture content and sieved to a size of $90-100 \mu \mathrm{m}$. The marble dust is primarily considered as low cost, easily available industrial waste.The chemical composition of the used marble powder as filler material based on weight percentage is presented in Table-1.

\section{Composite Fabrication}

The epoxy resin (LY 556) and hardener (HY 951) are mixed in weight ratio of 10:1 as recommended by the help of magnetic stirrer. The marble powders (MP) are incorporated in epoxy resin to prepare the 
RASĀYAN J. Chem.

Vol. 11 | No. 1 |80-87 | January - March | 2018

composite samples. The glass tube of cylindrical dimensions $30 \mathrm{X} 80 \mathrm{~mm}$ was wax coated and sprayed with uniform silicon releasing agent. The prepared mixture poured into the glass tubes. Composites, as shown in Table-2 with four different compositions, are made. The composite in the glass tube kept for $24 \mathrm{~h}$ at room temperature to be cast in hand layup technique. After curing at room temperature containers are broken and prepared samples are collected and cut as per the required dimension for thermal conductivity test.

Table-1: Chemical composition of marble particle

\begin{tabular}{c|c|c}
\hline S. No. & Chemical compound present & Percentage \\
\hline 1. & $\mathrm{LOI}$ & 41.92 \\
\hline 2. & $\mathrm{CaO}$ & 34.98 \\
\hline 3. & $\mathrm{MgO}$ & 18.96 \\
\hline 4. & $\mathrm{SiO}_{2}$ & 2.76 \\
\hline 5. & $\mathrm{Al}_{2} \mathrm{O}_{3}$ & 0.98 \\
\hline 6. & $\mathrm{Fe}_{2} \mathrm{O}_{3}$ & 0.4 \\
\hline
\end{tabular}

Table-2: Designation of composite samples

\begin{tabular}{c|c}
\hline Name of composites & Composition \\
\hline EM0 & Epoxy (100 vol. \%) +filler (0 vol. \%) \\
\hline EM1 & Epoxy $(98.6$ vol. \%) + marble powder (1.4 vol. \%) \\
\hline EM2 & Epoxy $(96.6$ vol. \%) + marble powder $(3.4$ vol. \%) \\
\hline EM3 & Epoxy $(93.5$ vol. \%) + marble powder $(6.5$ vol. \%) \\
\hline
\end{tabular}

\section{Experimental determination of thermal conductivity}

To measure the thermal conductivity of polymers, ceramics, composites, glasses, rubbers, some metals with low to medium thermal conductivity samples Untherm ${ }^{\mathrm{TM}} 2022$ model is used. Paste or liquid metals also can be tested by keeping it in a special container. The test was carried out as per ASTM E-1530 standards. ${ }^{32}$

\section{Working principle of Untherm ${ }^{\mathrm{TM}} \mathbf{2 0 2 2}$}

The test sample was kept between two surfaces, each with different temperature controlled and uniform compressive force was applied. The lower part is calibrated with het flow transducer. The heat flows through the test composite sample from upper plate to lower plate in axial temperature gradient under loading condition. Keeping at this condition for some time, the system reaches to a thermal equilibrium condition. The temperature difference subsequently recorded at the output by heat flow transducer. The temperature difference through the specimen is measured by the temperature sensor.

As the thermal conductivity was the measure of heat flow rate in a body with temperature constraint, the one-directional conduction formula can be established as given in Eq. (5):

$Q=K A\left(\frac{T_{1}-T_{2}}{x}\right)$

Where, $\mathrm{K}$ is the thermal conductivity (W/m K), A is the cross-sectional area $\left(\mathrm{m}^{2}\right), \mathrm{Q}$ is the heat flux (W), $\mathrm{T}_{1}-\mathrm{T}_{2}$ is the difference in temperature $(\mathrm{K})$ and $\mathrm{x}$ is the thickness of the sample $(\mathrm{m})$.

The heat resistance of specimen may be derived as:

$R=\frac{T_{1}-T_{2}}{Q / A}$

Where $\mathrm{R}$ is the resistance offered by the composite specimen between two plate surfaces at a different temperature range $\left(\mathrm{m}^{2}-\mathrm{K} / \mathrm{W}\right)$. From Equations (5) and (6) the Equation (7) can be derived as:

$K=\frac{x}{R}$

Due to the temperature difference between upper and lower plate, the heat flux transducer measure the value of $\mathrm{Q}$ in Untherm ${ }^{\mathrm{TM}} 2022$. The thermal resistance of the sample kept between these plates can be 
measured. With given thickness and cross-sectional area of samples, the thermal conductivity estimated using Eq. (7).

\section{Finite element method and ANSYS}

Finite element method (FEM) was used as a computational technique for a fairly accurate solution to various engineering problems having complex domains under general boundary condition. ${ }^{33}$ Structural analysis was conducted using ANSYS package to optimize the strength of truck chassis to reduce the vibration. ${ }^{34}$ FEA becomes an important technique to design and modeling of different problems related to real-world engineering discipline. An engineering problem may have a dissimilar phase with different variables. The field variable may change according to location creating an unlimited number of solutions in the domain. The FEM discretize the total domain to multiple sub-domains providing a fairly accurate solution by using the weighted residual method. FEM also expresses the field variables to assumed similar function within the limit. These functions are defined at precise points known as nodes. Generally, nodes are placed at sub-domain boundaries and connect nearer elements. The ability of FEM to divide the unbalanced elements into valuable elements and practical solution of various problems of engineering disciplines. The numerical procedure of FEM can also provide a solution to heat transfer analysis, stress/strain analysis, fluid flow problems etc. ANSYS is a powerful FEM tool used for solving all such type of static/dynamic problems under both linear and non-linear condition.

\section{Numerical Analysis}

\section{RESULTS AND DISCUSSION}

Thermal conduction analysis is made for heat transfer through the composite body using ANSYS. To carry out the thermal analysis, the cubic model (3-D) with spheres in cube lattice structure was used for different specimens. Numerically, the effective thermal conductivities of marble filled (6.5 wt \%) epoxy composites are evaluated using ANSYS.

\section{Determination of the problem}

Properties of the composite material are the principal requirement for design and application in any field. The microstructure of the composites is one of the important controlling parameters which can influence the properties up to a substantial extent. Microstructure tends to the shape, size, and orientation of the particles in the composites. Several composites contain inclusion of random distribution and the effective properties can be studied with periodic structure.

In numerical analysis of the problem, the temperature inside $\mathrm{ABCD}$ of the given model is chosen as $\mathrm{T}_{1}=100^{\circ} \mathrm{C}$ and the ambient temperature is $27^{\circ} \mathrm{C}$ with thermal conductivity as $2.5 \mathrm{~W} / \mathrm{m}^{2} \mathrm{~K}$. The boundary condition and heat flow direction are presented in Fig.-1.The external sides parallel along heat flow direction are assumed as adiabatic.

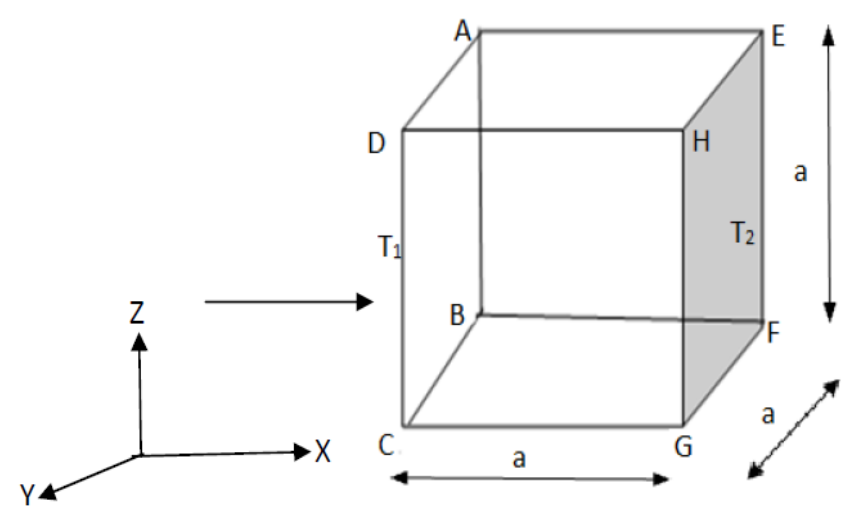

Fig.-1: Heat flow direction with boundary condition 
The temperature on the adiabatic boundaries and at the nodes in the internal zone is unknown. These temperatures are found using the ANSYS package. In the ideal case, it is assumed that the composite is isotropic, void-free; epoxy matrix and marble filler are macroscopically homogeneous, heat resistance between filler and matrix surface is negligible, the filler is distributed uniformly in the matrix. The thermal conductivities of the marble filled $(6.5 \mathrm{wt} \%)$ epoxy composites are theoretically estimated and the results are compared with the numerically designed values by using the sphere in cube lattice model and the experimental data. Applying FEM analysis using ANSYS, the temperature profiles obtained are presented in Figs.-2, 3,4 and 5, respectively. The thermal conductivity values of different marble powder filled composites obtained from the rule-of-mixture model, Maxwell's theorem and values obtained from FEM analysis are presented in Table-3. It shows the comparative data of effective thermal conductivities and the results obtained by FEM analysis are approximately closer to the experimental values in different samples.

Table-3: Effective thermal conductivities values obtained from different models

\begin{tabular}{c|c|c|c|c|c}
\hline Composites & $\begin{array}{c}\text { Marble powder } \\
\text { content (vol. \%) }\end{array}$ & \multicolumn{4}{|c}{ Effective thermal conductivities (W/m-K) } \\
\cline { 3 - 6 } & & $\begin{array}{c}\text { Rule of } \\
\text { mixture model }\end{array}$ & $\begin{array}{c}\text { Maxwell's } \\
\text { model }\end{array}$ & $\begin{array}{c}\text { FEM } \\
\text { model }\end{array}$ & $\begin{array}{c}\text { Experimental } \\
\text { value }\end{array}$ \\
\hline EM0 & 0 & 0.363 & 0.363 & 0.363 & 0.363 \\
\hline EM1 & 1.4 & 0.367 & 0.372 & 0.374 & 0.381 \\
\hline EM2 & 3.4 & 0.373 & 0.386 & 0.389 & 0.401 \\
\hline EM3 & 6.5 & 0.383 & 0.408 & 0.421 & 0.436 \\
\hline
\end{tabular}

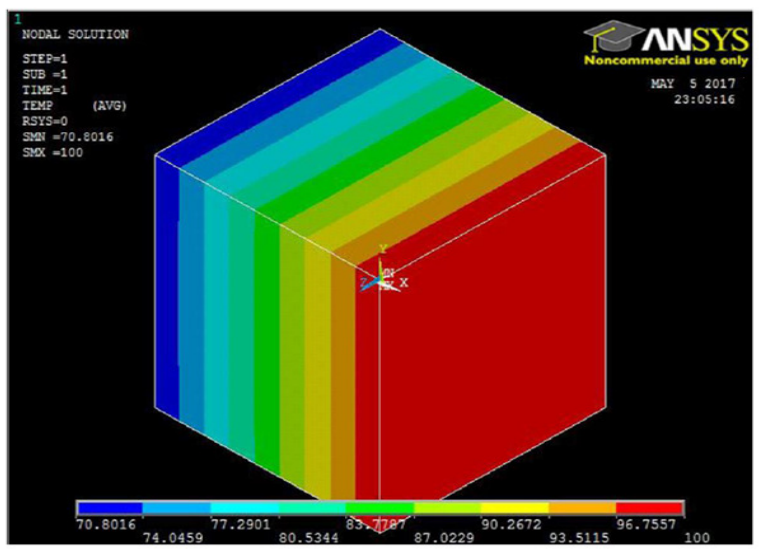

Fig.-2: Temperature profile of vol. $0 \%$ of marble particle composite

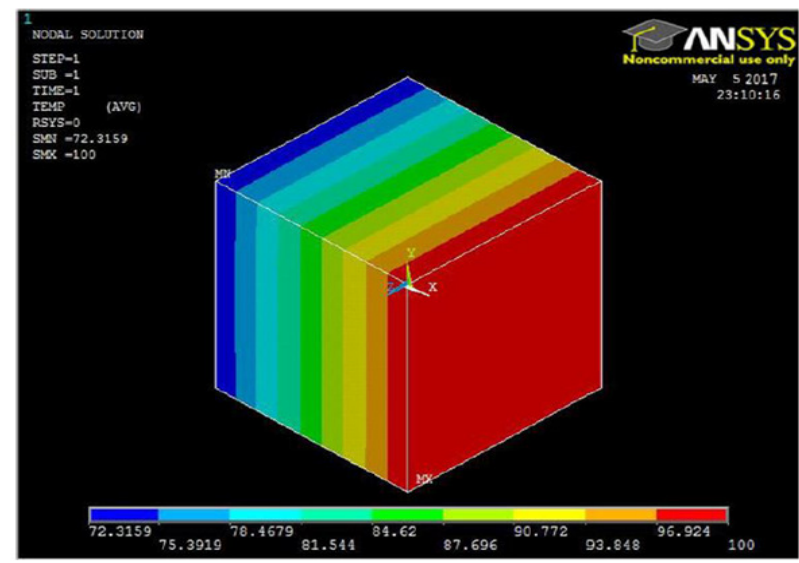

Fig.-4: Temperature profile of vol. $3.4 \%$ of marble particle composite

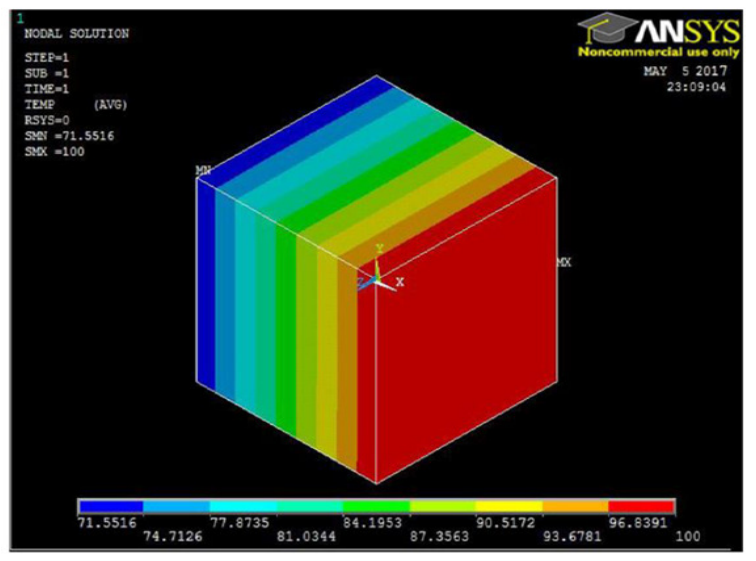

Fig.-3: Temperature profile of vol.1.4\% of marble particle composite

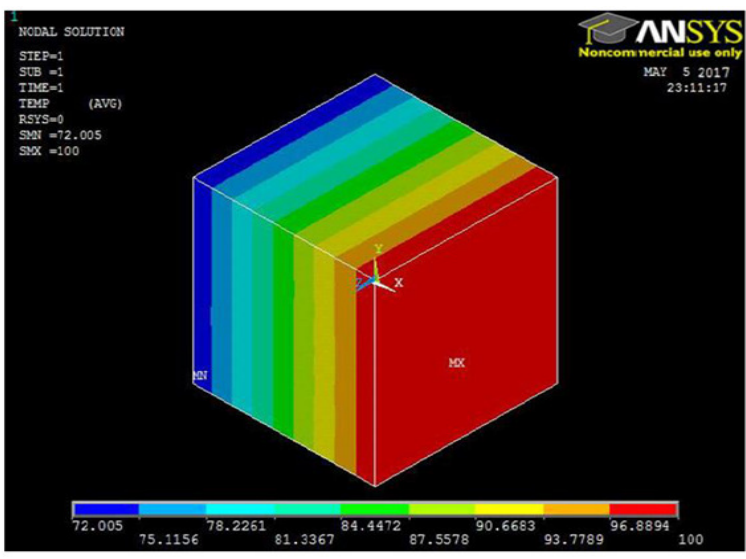

Fig.-5: Temperature profile of vol. $6.5 \%$ of marble particle composite 
RASĀYAN J. Chem.

Vol. 11 | No. 1 |80-87 | January - March | 2018

Table-4: Percentage error with respect to experimental thermal conductivity values

\begin{tabular}{c|c|c|c|c}
\hline Composites & $\begin{array}{c}\text { Marble powder } \\
\text { content (vol. \%) }\end{array}$ & \multicolumn{3}{|c}{ Percentage error with respect to experimental } \\
\cline { 3 - 5 } & & $\begin{array}{c}\text { Rule of } \\
\text { mixture model }\end{array}$ & $\begin{array}{c}\text { Maxwell's } \\
\text { model }\end{array}$ & $\begin{array}{c}\text { FEM } \\
\text { model }\end{array}$ \\
\hline EM1 & 1.4 & 4.72 & 2.36 & 1.83 \\
\hline EM2 & 3.4 & 6.98 & 3.74 & 2.99 \\
\hline EM3 & 6.5 & 12.5 & 6.42 & 3.44 \\
\hline
\end{tabular}

The thermal conductivity of the epoxy composites is improved about $4.9 \%$ to $20.1 \%$ by the addition of marble filler about 1.4 to $6.5 \%$ by volume as presented in Table-3.The existing models such as rule of the mixture and Maxwell's model showed the improvement in the thermal conductivity is about 5.5\% and $5.8 \%$ with $6.5 \%$ vol. of filler addition as compared with the neat epoxy sample. Using FEM model the thermal conductivity was improved about $15.9 \%$ with the addition of $6.5 \%$ marble powder with neat epoxy. The percentage error adopting different methods for the composites are presented in Table- 4 . After the comparative study, it is seen that the FEM model shows the error from 1.83 to $3.44 \%$, whereas in the rule of mixture model error shows 4.72 to $12.5 \%$ and Maxwell's model it is found within 2.36 to $6.42 \%$. Form the proposed model, it is concluded that for the particle filled composites, the FEM model can be suitable for finding the thermal conductivities for different filler percentage and suggested for engineering applications.

\section{CONCLUSION}

The theoretical, experimental and numerical investigation on marble powder filled epoxy composites with various weight proportions has to lead to following conclusions:

1. Composites containing epoxy resin filled with micro-sized marble particles can be fabricated by simple hand lay-up technique at room temperature condition.

2. The incorporation of waste marble powder results in improvement of the thermal conductivity of the epoxy-based composite. With the addition of 1.4 vol. \% of marble powder thermal conductivities increases by $4.9 \%$ and with $6.5 \mathrm{vol} . \%$ it improves by $20.1 \%$ with respect to neat epoxy.

3. The experimental thermal conductivities shows reasonable agreement with the values obtained from FEM analysis as compared with ROM and Maxwell's theorem various particle concentrations about 1.4 to 6.5 vol. $\%$.

4. As the percentage error was less in FEM model, this method is successfully suggested to determine the thermal conductivity with approximate closer values of these developed composites.

5. These developed epoxy-marble composites can be used for die (chip) attach, heat interface material, aerodynamic rotor blade, encapsulation, electrical cable insulation, electronic package, etc.

\section{REFERENCES}

1. C. Borsellino, L. Calabrese and G. Di Bella, Construction and Building Materials, 23(5), 1915 (2009).

2. N. Bilgin, H. A. Yeprem, S. Arslan, A. Bilgin, E. Günay and M. Marşoglu , Construction and Building Materials, 29, 449 (2012).

3. H. Akbulut, and C. Gürer, Building and Environment, 42(5), 1921 (2007).

4. H. Binici, H. Kaplan and S. Yilmaz, Scientific Research and Essays, 2(9), 372(2007).

5. M. Gürü, S. Tekeli and E. Akin, Key Engineering Materials, 336, 1353 (2007).

6. A. Aruniit, J. Kers , A. Krumme, T. Poltimäe and K. Tall, Materials Science, 18(3), 256 (2012).

7. A. Aruniit, J. Kers, D. Goljandin, M. Saarna, K. Tall, J. Majak and H. Herranen, Materials Science, 17(3), 276(2011).

8. I. Oral, Polymer Composites, 36(3), 584(2015).

9. B. Demirel, International Journal of Physical Sciences, 5(9), 1372 (2010). 
RASĀYAN J. Chem.

Vol. 11 | No. 1 |80-87 | January - March | 2018

10. G. Marras, N. Careddu, C. Internicola and G. Siotto, Global Stone Congress (2010).

11. J. I. Kim, P. H. Kang and Y. C. Nho, Journal of Applied Polymer Science, 92(1), 394 (2004).

12. S. Nikkeshi, M. Kudo and T. Masuko , Journal of Applied Polymer Science, 69(13), 2593(1998).

13. I. Tavman, Experimental Heat Transfer, Fluid Mechanics, and Thermodynamics, Elsevier, 1562(1991).

14. C. L. Choy and K.Young, Polymer, 18(8), 769(1977).

15. S. T. Peng and R. F. Landel, Journal of Applied Polymer Science, 19(1), 49(1975).

16. D. Hansen and C.C. Ho, Journal of Polymer Science Part A: Polymer Chemistry, 3(2), 659(1965).

17. A. Griesinger, W. Hurler and M. Pietralla, International Journal of Heat and Mass Transfer, 40(13), 3049(1997).

18. B. Weidenfeller, M. Höfer and F. R. Schilling, Composites Part A: Applied Science and Manufacturing, 35(4), 423(2004).

19. Y. Nagai, G.C. Lai, J. Ceram. Soc. Jpn., 105 (3),197 (1997) .

20. H. S. Tekce, D. Kumlutas and I. H. Tavman, In Proceedings of the 10th Denizli Material Symposium, Denizli, 296(2004).

21. D. Kumlutaş, I. H. Tavman and M. T. Çoban, Composites Science and Technology, 63(1), 113(2003).

22. S.K. Basha, et al., Rasayan J. Chem., 10(1), 279(2017).

23. N. Maragani, K.Vijaya Kumar and N. KrishnaJyothi, Rasayan J. Chem., 10(2), 665 (2017).

24. A. Patnaik, M. Abdulla, A. Satapathy, S. Biswas and B. K. Satapathy, Materials \& Design, 31(2), 837(2010).

25. Y. P. Mamunya, V. V. Davydenko, P. Pissis and E.V. Lebedev, European Polymer Journal, 38(9), 1887(2002).

26. N.M. Sofian, M. Rusu, R. Neagu and E. Neagu, Journal of Thermoplastic Composite Materials, 14(1), 20(2001).

27. H. J. Ott, Plastics and Rubber Processing and Applications, 1, 9 (1981).

28. R. C. Progelhof, J. L. Throne, and R. R. Ruetsch., Polymer Engineering \& Science 16(9),615(1976).

29. Y. Agari, and T. Uno, Journal of Applied Polymer Science, 32(7), 5705(1986).

30. Y. Agari, A. Ueda and S. Nagai, Journal of Applied Polymer Science, 43(6), 1117(1991).

31. J. C. Maxwell, Electricity and Magnetism Clarendon Press, (1873).

32. ASTM E 1530-99, Standard test method for evaluating the resistance to thermal transmission of materials by the guarded heat flow meter technique, ASTM International, PA 1999.

33. M.J. Turner, R.W. Clough, H.C. Martin, L.J. Topp, J. Aeronaut. Sci., 23(9), 805 (1956).

34. A. Vinod, et. al., Rasayan J. Chem., 10(2), 521(2017).

[RJC-1952/2017] 